\title{
EL PARAÍSO IBICENCO Y RAFAEL AZCONA
}

\author{
Juan A. RÍOS CARRATALÁ
}

Universidad de Alicante

\section{RESUMEN}

Rafael Azcona, poco antes de fallecer, rescribió sus novelas publicadas entre mediados de los años cincuenta y principios de los sesenta. Esta circunstancia nos ha facilitado la oportunidad de valorar más ajustadamente la aportación de un autor eclipsado por su faceta como guionista cinematográfico. Los europeos, tal vez su obra más ambiciosa desde un punto de vista literario, nos remite a un tiempo donde el contacto con el incipiente turismo contrastaba con un franquismo que iba más allá de lo político y lo ideológico.

Palabras clave: Rafael Azcona, novela, Los Europeos, franquismo.

\begin{abstract}
Rafael Azcona rewrote, before expiring, his novels published in the fifties and sixties. Los europeos, probably his more ambitious work from the literary point of view, reflects a time in which the contact with the newly found tourism was contrasting with the political and ideological reality of the Franco's regime.

Key words: Rafael Azona, novel, Los Europeos, Franco's regime.
\end{abstract}

¡Sesenta días de cachondeo! ¡Mi padre a miles de kilómetros, nosotros con dinero, y a nuestro alrededor una cohorte de mujeres sumiéndonos en el deliquio amoroso! La isla está llena hasta los topes de extranjeras enloquecidas por el fuego del sol y de los hombres de España, Miguel... ¡Dos meses en el paraíso, en un paraíso que se llama Ibiza! (Azcona, 1960:18) 
Rafael Azcona (Logroño, 1926-Madrid, 2008) dominaba el arte de la anécdota. Como tertuliano, sabía utilizar este recurso cuando era pertinente y en sus respuestas a los periodistas lo empleaba para alumbrar cuestiones que, de otra manera, habrían necesitado de prolijas explicaciones. Su bagaje de anécdotas propias y ajenas era excepcional. Rafael Azcona lo acumuló gracias a la riqueza de sus lecturas y las muchas horas de tertulia, dos de las fuentes que le abastecían como creador de tantos personajes. Sus contertulios percibían que disfrutaba contándolas, con el afán de compartirlas y la sonrisa de quien parece descubrir de nuevo algo curioso, paradójico y capaz de suscitar una reflexión nunca incompatible con el humor. La realidad le sorprendía todos los días, después de alegrarse cada mañana por seguir vivo y dispuesto a contar nuevos sucedidos. El final de cada anécdota relatada por Rafael Azcona era una chispa que mantenía la sonrisa y anunciaba nuevas paradojas de una vida absurda a menudo, pero que el autor riojano nunca se cansó de observar y descubrir.

Desde que nos conocimos en el año 2000 hasta su fallecimiento, tuve la oportunidad de conversar con Rafael Azcona en varias ocasiones. Fue un privilegio, también considerado como tal por muchos de quienes disfrutaron de su amistad. Creo, asimismo, haber leído casi todas las entrevistas que concedió cuando, durante sus últimos años, optó por la visibilidad. Algunas de sus anécdotas más conocidas las he incorporado a mi bagaje personal porque revelan una filosofía a ras de suelo, estrictamente vital, que comparto y hasta intento transmitir. Mi ensayo titulado La sonrisa del inútil (2008) es una consecuencia de, entre otras, esa influencia del amigo donde nunca había teoría ni disquisiciones. Rafael Azcona era incompatible con lo abstracto, lo solemne y lo aburrido. Argumentaba con anécdotas o casos tan verídicos como sorprendentes, que conocía, anotaba y perfilaba con pocos rasgos bien seleccionados y una lucidez propia de sus años de atento observador de la realidad. Sus ideas no sólo resultaban corpóreas y hasta palpables con sus tres dimensiones. Como buen guionista, también las hacía ver a sus contertulios entre sonrisas compartidas. El resultado era una prueba de la confianza que transmitía a quienes lo animaban a charlar.

Con motivo de un encuentro en Murcia durante la primavera de 2006 y después de leer su nueva versión de Los europeos (2006), le pregunté por sus experiencias en la Ibiza de finales de los años cincuenta y principios de los sesenta. Ya sabía de sus largas y reiteradas estancias, hasta 1964, en una isla todavía ajena a la actual explotación turística, donde compartió un tiempo de amistad con Ignacio Aldecoa, su esposa Josefina, Fernando-Guillermo de Castro y otros peninsulares que acudían al paraje mediterráneo como una 


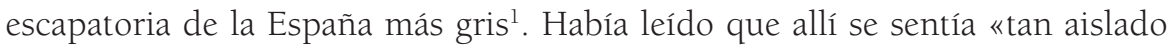
como libre», pues era «un sitio muy habitable» y barato donde «las extranjeras te sonreían cuando les sonreías y te hablaban cuando les hablabas sin pensar que eso era pecado mortal» (Harguindey, 1998:73). Aquella sonriente reacción se le quedaría grabada, pues la rememoró en numerosas ocasiones. A raíz de mis preguntas, Rafael Azcona recordó de nuevo la dificultad para sentarse ante una máquina de escribir cuando estaba en Ibiza. La vida alrededor era demasiado sugerente. Terminó empeñando su instrumento de trabajo para conseguir un dinero que le permitiera seguir en la isla. También me habló de la feliz incomunicación con el resto del mundo, la facilidad para conocer personas procedentes de diferentes lugares que acudían al reclamo de un espacio más libre, lo barato de las noches dedicadas a la bebida mientras ligaba con éxito disimulado por su natural modestia... Rafael Azcona hablaba a base de anécdotas divertidas, pero en definitiva coincidía con lo afirmado al respecto por su amiga Josefina R. de Aldecoa:

La isla era el resumen de todo lo que se nos negaba en el Madrid de aquella época. Un clima moral relajado. Un ambiente social cosmopolita de verdad. Extranjeros que vivían un exilio voluntario en las calas azules de la isla, ajena todavía a la agresión turística multitudinaria.

Ibiza era la alegría física de vivir. Días de mar y sol, de barcos de amigos para navegaciones cortas a calas bellísimas. Noches de copas y navegaciones largas por las mareas exaltadas de la imaginación, con personajes irrepetibles y amigos inolvidables. Todos nos sentíamos declassés y far out. Y libres. Nunca como en la isla he sentido el significado de la libertad personal, lejos de la tristeza y la mediocridad del Madrid deprimente de la posguerra. Éramos alegres porque éramos jóvenes y habíamos descubierto el atractivo esplendoroso de una isla que destacaba radiante en medio del mar Mediterráneo (Castro, 2003:10).

Rafael Azcona contaba aquella experiencia de juventud con menos carga lírica. Le gustaba resumirla con la síntesis propia de las buenas anécdotas. Gracias a las mismas, reímos a lo largo de aquella tarde pasada en una cafetería de Murcia y le pregunté si, transcurridos casi cincuenta años desde entonces, consideraba la

1. Fernando-Guillermo de Castro acompañó a Rafael Azcona en su viaje a Ibiza durante el verano de 1957 (2003: 30-45) y, por los datos que aporta, es fácil deducir que esa experiencia y la de otros veraneos posteriores fue decisiva para la creación de Los europeos: «Aquel verano [1957] nos instalamos en la pensión Catalina, que yo conocía. Sería al siguiente año cuando convinimos alquilar a medias un apartamento en el centro del pueblo. Rafael y yo, en San Antonio, vivimos juntos, compartiendo un mismo piso, tres veranos seguidos, por lo menos, si bien cada año mudamos de casa» (p. 30). No obstante, el amigo del novelista no reconoce abiertamente esa relación entre la realidad y la ficción y, sobre todo, no se siente identificado con un personaje como pudiera ser Antonio. La relación de amistad terminó mal y, después de leer La isla perdida, comprendemos que las diferencias entre su autor y Rafael Azcona eran paralelas a las que contraponen a Miguel y Antonio, los protagonistas de la citada novela.

Anales, 21, 2009, pp. 161-173 
isla del Mediterráneo, tan distinta ahora, como una especie de paraíso perdido. Rafael Azcona me contestó que todos los paraísos andan perdidos, salvo que mantengamos la ingenuidad del iluso o el cinismo del falsario. Añadió que, en aquella Ibiza todavía virgen, había un amplio espacio para la tragicomedia que tanto nos gustaba, para esa contradictoria mezcla de la que se alimenta su creación literaria y cinematográfica porque es coherente con la realidad de la que parte.

Los europeos (1960) es un ejemplo novelístico de la distancia que media entre la realidad y lo paradisíaco ${ }^{2}$. Sus dos protagonistas, Antonio y Miguel, parten de un Madrid tórrido, vulgar y hasta agobiante en busca de la libertad, que asocian a la facilidad para conquistar extranjeras supuestamente ávidas de sexo. Ambos amigos son jóvenes y solteros, disponen de dinero fresco y tiempo para disfrutar del verano de 1958. El Madrid en el que viven, en condiciones contrapuestas por su diferente adscripción social, les permite pensar que cualquier alternativa puede resultar paradisíaca. Ibiza se convierte así en una tierra prometida, donde las vagas promesas de felicidad se concretan en mujeres, alcohol y sol para un tiempo sin compromisos, ceremonias ni obligaciones. El problema es que, a ese paraíso, Antonio y Miguel no llegan limpios de contradicciones o limitaciones.

El viaje desde el puerto de Valencia hasta Ibiza, con episodios entre el tremendismo y la picaresca, dista mucho de ser purificador. Ni siquiera supone una aventura con desenlace feliz. La clave del frustrante resultado reside en que esta pareja, tan aparentemente contrapuesta, arrostra una mediocridad como individuos de un Madrid mesetario que nunca queda atrás. Como recordara el quevedesco Pablos en el final de El Buscón (1626), cuando decide pasarse a Indias «a ver si, mudando mundo y tierra, mejoraría mi suerte», el empeño es imposible, «pues nunca mejora su estado quien muda solamente de lugar, y no de vida y costumbres». Antonio y Miguel mudan de lugar, vida y costumbres, pero mantienen una mentalidad de la que resulta difícil desprenderse. La misma no es fruto del destino, como en los deterministas relatos de la picaresca, sino de un contexto histórico fácil de adivinar. La mediterránea luz de Ibiza queda así oscurecida por un tiempo de represión, machismo y mediocridad que arrostran los protagonistas. Rafael Azcona disfrutó, y mucho, en aquella isla junto con sus amigos. Lo recordaba con una sonrisa, pero nunca dejó de ser consciente de las contradicciones de una realidad donde no cabían los espejismos del ideal, ni siquiera el paradisíaco. Los europeos prueba esa temprana lucidez.

2. Incluyo un análisis de la versión original de la novela en mi Introducción a la obra literaria de Rafael Azcona (2005: 81-94), por lo que en esta ocasión me limitaré a las cuestiones que en dicho trabajo, anterior a la definitiva versión de Los europeos, no pude abordar.

Anales, 21, 2009, pp. 161-173 
Antonio es un tarambana de veintisiete años que vive de la fortuna de su padre mientras ejerce como eterno aspirante a estudiante de Arquitectura. Su única preocupación, obsesiva hasta la comicidad, es acostarse con las míticas extranjeras de Ibiza, aunque por el camino está dispuesto a hacerlo con cualquier otra hembra. En la versión original de la novela, este objetivo es evidente a pesar de la autocensura que condicionó a Rafael Azcona. El personaje, en el improbable caso de que hubiera existido una adaptación cinematográfica, podría haber sido interpretado por alguno de los actores españoles que ponían los ojos en blanco a la vista de un bikini, daban rienda suelta a su agobiante labia y se mostraban como unos patéticos obsesos para regocijo de los espectadores. Estos rasgos, como todos los fundamentales de la novela, se mantienen en la versión publicada en 2006. Sólo aumenta el grado de explicitud de una actitud ya sin eufemismos, reveladora del machismo galopante de tanto reprimido que acudía al reclamo de una isla donde las mujeres, por extranjeras, debían ser «fáciles».

Antonio es impulsivo, inquieto y no admite razones que puedan distraerle de su único objetivo: «El Mare Nostrum. Y en sus aguas, Europa en bikini, Miguelito» (2005:23). También aparece ante el lector como un sujeto poco agraciado en lo referente al aspecto físico, fracasado en sus asechanzas sexuales sin que merme su entusiasmo y alejado del canon de la virilidad a la moda en la época del incipiente turismo. Su única esperanza de ligar radica en la insistencia hasta el agotamiento. Sin embargo, Antonio nunca teme aparecer como patético y, convencido de la misión para la que ha nacido, decide consagrarse a la misma durante el verano de 1958 en compañía de su amigo: «Lo quieras o no, con bikinis o sin ellos, hoy empieza tu redención. Porque tú, como todos los españoles, eres un cachondo irredento» (2006:81).

Miguel ya ha cumplido los treinta años, vive en una pensión madrileña cuyo ambiente nos recuerda el recreado en El pisito (1957) y trabaja como delineante a las órdenes del padre de Antonio. Desde el principio de la novela, aparece como un personaje contrapuesto a su amigo. Ambos comparten juventud y ganas de divertirse, pero Miguel es un sujeto al que hemos conocido en pijama mientras tiende sus calcetines recién lavados a mano y soporta las lamentaciones de su casera. Este tipo de circunstancias, aparentemente anecdóticas y de clara influencia cinematográfica, marcan a los personajes en las creaciones de Rafael Azcona. A partir de las mismas y con una hábil dosificación por parte del narrador, el delineante se muestra más reservado y sosegado que su ocioso amigo, incluso reitera que su intención es descansar durante el veraneo. El autoengaño todavía funciona porque no ha sido puesto a prueba.

El viaje a Ibiza en un viejo barco se transforma en una especie de via crucis, como si fuera el preámbulo de lo que vendrá después. Miguel tiene problemas 
con sus callos, le molestan las alpargatas que Antonio le ha obligado a comprar para estar a la moda, protesta ante la perspectiva de llegar a la isla cargado con unas ensangrentadas banderillas y una montera, las incomodidades sufridas en el trayecto le resultan insoportables, apenas puede descansar y, frente al entusiasmo de Antonio, muestra un lúcido escepticismo. Miguel se convierte así en un personaje pasivo, pero también cómplice por su incapacidad para decir no y acabará contagiándose de la actitud de su amigo. Nunca aparecerá hiperactivo a la caza y captura de la presa fácil, como tantos obsesos que tiene la oportunidad de conocer en la isla. No es su estilo, pero actuará con similares o peores consecuencias para las mujeres porque comparte buena parte de la reprimida mediocridad de quienes, como Antonio, le han arrastrado sin demasiada oposición.

La estancia en Ibiza de ambos amigos se convierte en una temporada de caza y captura donde no hay tiempo para el desaliento. Las posibles presas son todas las mujeres que se cruzan por delante. El impulsivo Antonio y el mucho más discreto Miguel se distinguen entre sí por las formas, pero comparten un objetivo omnipresente y hasta obsesivo. En la versión original, sometida a la autocensura, ya se evidencia con claridad esta circunstancia, mientras que, en su reelaboración de 2006, Rafael Azcona acude a una explicitud fácil de imaginar. El vocabulario es más directo y las acciones son narradas sin recurrir al eufemismo, aunque ya en el texto publicado, supuestamente, en el París de 1960 todo quedaba claro ${ }^{3}$. El resultado fue la censura sin mediar expediente administrativo, la práctica desaparición de una novela donde apenas quedaba hueco para algo más que un deseo sexual convertido en una obsesión de cuyo machismo, por obvio, sólo cabe la constatación. Era el de tantos jóvenes españoles de la época que acudían a las playas de los albores del turismo. Gesticulantes y algo patéticos, iban a la búsqueda de «las extranjeras», presas más accesibles que unas españolas obligadas a ser decentes.

Numerosas comedias cinematográficas de los años sesenta se centrarán en este fenómeno y hasta aparecerá un subgénero, «el landismo», con Alfredo Landa como icono de un tipo representativo desde el punto de vista sociológico. Su enorme éxito popular evidencia la raíz de un comportamiento que produce bochorno. La diferencia fundamental entre estas películas y la novela de Rafael Azcona es que las primeras sólo buscan la comicidad hasta llegar a desenlaces abiertamente reaccionarios. Lejos de plantear una crítica o una alternativa, pare-

3. Ante la imposibilidad de publicar la novela en España, el editor Ricardo Baeza, por entonces en la oposición política junto a Dionisio Ridruejo, ideó la estratagema de publicarla con un falso pie de imprenta localizado en París. El voluntarismo no impidió que Los europeos se convirtiera prácticamente en una novela clandestina de muy escasa circulación. Así se justifica la escasez de estudios, cuando en realidad es una de las mejores creaciones de la generación realista encabezada por Ignacio Aldecoa. 
cen congraciarse con una situación donde el españolito de turno podía parecer patético pero, al final, recibía su recompensa por vía matrimonial. Claro está que después de renunciar a unas aventuras imposibles, sólo apuntadas y nunca culminadas para provocar la risa.

Rafael Azcona, como autor, también ríe a menudo con estas situaciones. Incluso planteará una, hasta cierto punto, parodia de las mismas en Vivan los novios (1969), de Luis García Berlanga. Sin embargo, es evidente su distanciamiento con respecto a la mentalidad de los protagonistas, capaces de sostener unas relaciones donde el deseo se convierte en obsesión y la represión en una violencia, mental o física, cuya destinataria es siempre la mujer. El novelista, fiel a sus principios creativos, se niega a incluir cualquier digresión crítica. Tampoco hay un espacio para la enseñanza moral o ideológica. Resultan innecesarias, ya que la adecuada presentación de los hechos protagonizados por Antonio y Miguel basta para incitar a una reflexión por parte del lector, probablemente sorprendido y asqueado ante unos cazadores que acaban huyendo de sí mismos y, por el camino, se llevan a varias inocentes de perfiles desdibujados. Son mujeres, y como tales sólo aparecen a modo de referencias para perfilar a los personajes masculinos, los únicos de los que se atrevía a escribir un Rafael Azcona prudente a la hora de abordar lo que desconocía o le hacía dudar. Algunos han confundido esta prudencia con una absurda misoginia.

Antonio, inasequible al desaliento como un personaje del landismo, se pone manos a la obra nada más llegar a Ibiza. La excitación se traduce en urgencia. Aunque miope, valora, pondera y planifica las posibilidades con cada mujer al alcance de su atenta mirada. Antonio sabe lo que quiere y no admite negativas. Su insistencia le permite obtener algunas recompensas, siempre menores, mientras que Miguel, casi sin proponérselo y hasta con dudas, se acuesta con una valenciana despechada y peluquera. Vicenta, o Vicen, no es la valkiria soñada, pero el abúlico delineante se entretiene con ella a la espera de una conquista más sugestiva.

La aparición de una joven francesa, Odette, supone un giro argumental que cambia el tono de la novela. Hasta entonces, Rafael Azcona hace uso de sus dotes para el retrato costumbrista. Los apuntes sobre la pensión donde vive Miguel y la descripción de la noche madrileña durante el verano nos permiten comprender el ansia de escapatoria que lleva hasta Ibiza a los dos amigos. Durante los primeros capítulos, también hemos navegado en el incómodo barco que hace la travesía, hemos sabido de la picaresca para aprovechar mejor el dinero y, sobre todo, el narrador nos recrea varias escenas capaces de darnos la imagen de una isla donde convivían culturas y mentalidades contrapuestas. La primera mitad de Los europeos se desenvuelve en los parámetros del retrato coral, que Rafael 
Azcona elevó hasta su máxima altura en algunos de los guiones escritos poco después. Sin embargo, la aparición de Odette y su influencia en Miguel suponen una nueva orientación de la novela. El narrador no deja de prestar atención a una fauna verdaderamente variopinta. Aparece retratada a partir de esos detalles que el autor riojano sabía escoger para definir a sus personajes sin apenas describir, basándose en la observación aparentemente trivial. Seguimos disfrutando con ese colectivo de españoles con los ojos fuera de órbita y extranjeros a la búsqueda de una aventura exótica. No obstante, la atención se focaliza a partir de este momento en la relación entre Odette y Miguel. Antonio queda relegado a un segundo plano porque es un personaje tan obsesivo como carente de posible desarrollo, aunque en el desenlace muestra una parcial rectificación. Ya conocemos, además, lo fundamental de Ibiza. Sus visitantes seguirán apareciendo como telón de fondo, como voces que contrapuntean una relación donde el deseo y los sentimientos juegan al equívoco, entre silencios y medias verdades que terminarán de manera trágica. También fría, porque Rafael Azcona nunca gustó de la espectacularidad de los desenlaces melodramáticos y se mantuvo fiel a la contención que le caracterizaba a la hora de escribir.

Odette es una joven de París, independiente, tímida y peculiar. En un clima de banalidad y ansias de juerga a cualquier precio, la francesa de belleza frágil aparece y desaparece sin apenas armar ruido. Discreta y un tanto enigmática, se la ve en cualquier rincón leyendo mientras toma limonadas, fuma cigarrillos negros y permanece en una soledad apenas alterada por algunos saludos, pronunciados con su rudimentario español. Ese distanciamiento con respecto al prototipo de las extranjeras soñadas por Antonio es el que seduce a Miguel, agobiado ante la perspectiva de alternar con mujeres desbocadas y más predispuesto al sosiego. Se inicia así una relación donde resulta difícil delimitar el papel de los sentimientos y los deseos, pero que acabará revelando la verdadera personalidad de un delineante hipócrita por mediocre que, hasta entonces, sólo era el contrapunto mesurado de Antonio.

La relación entre Odette y Miguel cuaja desde el principio, sin necesidad de estrategias para la conquista y con la naturalidad cultivada por una joven capaz de desconcertar a su amante. Éste pierde su independencia y, como suele ser habitual en los relatos de Rafael Azcona, empieza entonces a tener problemas. Tal vez porque descubre que el verdadero problema es él mismo, su inmadurez para afrontar una relación donde todo se complica a partir del embarazo de la joven. Esta circunstancia, apenas hace falta recordarlo, era especialmente problemática en la España de la época. Rafael Azcona sabía que su recreación novelística le traería problemas a la hora de la publicación, pero recrea el episodio del aborto con toda su crudeza, como nunca antes se había hecho en la literatura española. 
El resultado fue una novela prohibida que debió editarse con un falso pie de imprenta, en un supuesto París al que hubiera regresado Odette con su historia.

No obstante, lo fundamental no es el relato de un aborto que lleva a la pareja hasta una Barcelona de pensiones tétricas y personajes acordes con un mundo subterráneo, apenas presente en la imagen más o menos oficial de la época. Rafael Azcona se siente concernido por una circunstancia que, tan a menudo, se convertía en la otra cara de las relaciones entre parejas. Sabe del miedo a lo clandestino y realizado en condiciones de extrema precariedad, pero se centra en el egoísmo y la cobardía de un personaje como Miguel, hasta entonces mucho más atractivo que su amigo Antonio.

El delineante se niega a asumir su responsabilidad y deambula entre el desconcierto y el cinismo. Miguel disimula con Odette, siempre callada y nunca exigente; tan radicalmente distinta a la Ninette llevada a los escenarios por Miguel Mihura en 1964. Ella no es la personificación de un sueño masculino ni cultiva las artimañas de su compatriota para acabar casada y en Murcia. Odette no pretende enredar a su españolito, sino que se deja llevar sabiendo que no puede controlar la situación. Al final, el aborto se realiza en una Barcelona descrita con precisión y sabiduría en la última parte de la novela. Son momentos dramáticos que Rafael Azcona controla con una prosa cuya sobriedad agradecemos. La frialdad es imprescindible para comprender la reacción de un Miguel que, incapaz de compartir un sentimiento, sólo respira aliviado cuando Odette toma el tren que la devolverá a París, con una promesa de reencuentro de la que ella misma duda.

Nada más salir de la estación, Miguel rompe el papel con las señas de la muchacha. No piensa cumplir su compromiso porque es un amante mediocre, al menos en el aspecto sentimental. El delineante participa de una mentalidad egoísta en cuyo trasfondo, como un marco sólo sugerido, observamos una época reflejada por un autor que siempre tuvo la voluntad del realismo crítico, compartida con otros novelistas de su generación de cuya amistad disfrutó en tantas tertulias. Esa misma noche, cuando el rostro de Odette todavía era una imagen del presente, Miguel acaba en la sesión golfa de El Molino barcelonés, en compañía de un Martín ya avejentado que combatía con alcohol y mujeres el temor a las letras devueltas por los bancos. El delineante no sólo vuelve al punto de partida, sino que acaba peor que su amigo Antonio. El viaje ha sido estéril; el contacto con un mundo distinto sólo ha conseguido destapar lo peor de su personalidad. Faltaba mucho, a tenor de lo visto en una novela desoladora, para que tipos como Miguel pudieran ser «los europeos».

Las críticas y entrevistas publicadas con motivo de la aparición de la nueva versión insistieron en presentar la novela como un retrato de una época y un país 
de costumbres irrespirables. Rafael Azcona era consciente de la enorme diferencia entre la España donde la novela fue prohibida y la de una etapa de libertades democráticas, que nunca terminó de observar sin salir del asombro. Le gustaba comentarlo, entre sonrisas que invitaban al optimismo y recurriendo siempre a alguna anécdota. Aquella Ibiza de su época había desaparecido. Ni siquiera era un recuerdo para buena parte de sus posibles lectores, pero Rafael Azcona se sintió rejuvenecer mientras reescribía un texto olvidado durante décadas y consideró que, acentuando los rasgos que provocaron su censura, le devolvía la integridad con que debió aparecer: «creo que le he restituido todo lo que la autocensura le sisó», declaró en El Cultural (15-VI-2006).

La labor de reescritura, en este caso, es menos profunda que en otros que le permitieron recuperar y editar de nuevo el conjunto de las obras que escribió durante sus inicios, cuando todavía el cine no le había acaparado ${ }^{4}$. La historia de Los europeos no sufre alteraciones sustanciales, pero hay un metódico peinado del texto a la búsqueda de un lenguaje más directo y explícito; incluso más actual por su voluntad de dirigirse a un lector coetáneo. Y, sobre todo, Rafael Azcona demuestra una vez más su maestría en el arte del diálogo, que ocupa más del ochenta por ciento de la totalidad de una novela (Muro, 1997:185) escrita con la experiencia de cincuenta años de guiones.

El diálogo de Los europeos está repleto de detalles y connotaciones a la búsqueda de «una profundidad de campo», en términos cinematográficos, poblada por numerosos tipos representativos del momento. También nos remiten a una mentalidad y una época que el autor recupera para brindarla a sus lectores. Sin comentarios o apostillas del narrador, con la voluntad del mismo de quedar en un segundo plano porque sabía que sus personajes, como los de las películas, se definían por la palabra y las acciones. El resultado es desolador, el más amargo de cuantos aportó durante su etapa literaria, pero el testimonio adquiere un considerable valor literario y una todavía más notable capacidad para proyectar en el recuerdo una época y un país.

Rafael Conte titulaba «Azcona, escritor realista» su reseña publicada en El País (5-VIII-2006). Es uno de los pocos aciertos de un texto crítico con errores y erratas capaces de sonrojar, pero le permite así enlazar la novela del riojano con la de su amigo Ignacio Aldecoa, que también dedicó varias de sus obras a la experiencia vivida en Ibiza. En este caso, en la reescritura, la diferencia es que la voluntad realista y testimonial se compagina con el ejercicio de la memoria.

4. La tarea de reescritura comenzó a dar sus frutos en 1999 con la publicación del volumen Estrafalario/1, que recopilaba tres obras: Los muertos no se tocan, nene, El pisito y El cochecito. La buena acogida crítica obtenida facilitó que Rafael Azcona completara esta tarea con la inclusión de casi todas las obras literarias escritas durante su primera etapa. 
Rafael Azcona estaba acostumbrado a reelaborar sus guiones escritos en colaboración con los directores. Nunca tuvo problemas al respecto y sabía de lo provisional de cualquier texto. En Los europeos, que pudo haberse convertido en una película de la mano de Luis García Berlanga, esa colaboración es la de un novelista de ochenta años con su propia personalidad creadora de una etapa anterior. Lo sustancial permanece porque su valor testimonial es obvio y hasta recomendable para entender una época. Sin embargo, en su formulación literaria percibimos unos aires de libertad y modernidad que nos indican hasta qué punto Rafael Azcona no sólo trabajó hasta el último día, sino que también fue capaz de evolucionar a tenor de los tiempos.

A menudo, y a instancia de los periodistas, el guionista riojano rechazó cualquier atisbo de añoranza, tanto en lo personal como en sus creaciones cinematográficas o novelísticas. Esa predisposición a vivir el presente amplió su círculo de amistades, le granjeó la admiración de nuevas generaciones de creadores y tuvo su correlato literario, el de un sólido lector y un experimentado guionista que, sólo al final de su carrera, disfrutó de la oportunidad de escribir en libertad y con las debidas condiciones. En 2006, la autocensura quedaba lejos, no había plazos perentorios para la entrega de los originales, contaba con el apoyo de una buena editorial como Tusquets... Rafael Azcona recuperó así un tiempo remoto, pero también se resarció de la frustración sufrida como «escritor», su primera y fundamental vocación a la hora de ganarse la vida. Lo recordaría en numerosas entrevistas sin caer nunca en la lamentación.

La lectura de Los europeos nos remite a un franquismo en estado puro. Ya no es el régimen de la Victoria, disfrazado con vestimentas épicas adquiridas en un baratillo ideológico, sino el de la mediocridad resignada que se prolongó hasta su lenta agonía. Rafael Azcona lo recreó con la sabiduría del observador atento al detalle y el creador capaz de sintetizar gracias a la anécdota, a lo aparentemente superficial, pero que en realidad nos remite a la médula de una época. Sus mejores guiones y novelas como la aquí comentada son un ejemplo que conviene recuperar para alimentar una memoria histórica tan necesitada de lo concreto, lo visual y hasta palpable. El carácter coral de estas obras abunda en personajes anecdóticos y episodios colaterales. Una lectura superficial nos podría llevar a pensar que se presentan deslavazados, pero la mano maestra de Rafael Azcona los agrupa con una coherencia que nos remite a una imagen única: la mediocridad de una época de carencias y limitaciones, marcada por una represión que fue mucho más allá de lo político o ideológico. En Los europeos no se habla del franquismo, pero se percibe en cada detalle de una experiencia que hoy nos asombra y entonces formaba parte del ámbito costumbrista. Antonio y Miguel comparten una ignorancia absoluta en temas de calado a la hora de definir aquel período, 
pero evidencian en su comportamiento una mentalidad que no podemos considerar privativa del franquismo, aunque acentuó sus rasgos más negativos gracias al mismo.

Rafael Azcona manifestó en repetidas ocasiones que la censura era un mal absoluto. La padeció a menudo y, lo que es peor, tuvo que asumir la autocensura para intentar sacar adelante sus obras hasta que, ya en la década de los sesenta, se marchó a Italia con el objetivo de trabajar allí durante una larga temporada. Frente a lo pensado por otros colegas, nunca creyó que esa forma de represión agudizara el ingenio, ni siquiera que fuera un acicate para buscar nuevas vías de expresión. Rafael Azcona prefería una creación aireada y libre porque era la única forma de plasmar con eficacia su voluntad realista. Siempre fue coherente con esa intención y su habilidad para sortear los problemas durante la primera etapa todavía nos sorprende. El resultado es un conjunto de novelas y guiones, situados entre finales de los años cincuenta y principios de los sesenta, que constituyen uno de los frescos más notables de la mediocridad franquista, de esa España casposa que se resistía a entrar en la modernidad, tan aparente, del desarrollismo y el turismo. Los europeos es un excelente ejemplo, devuelto con la agilidad de un estilo narrativo renovado, un lenguaje directo y una maestría para el diálogo que ningún otro autor coetáneo llegó a alcanzar. Sólo Ignacio Aldecoa, en el caso de que la muerte prematura no se hubiera cruzado en su destino, estaba preparado para esa empresa. Tal vez, supongo, algún otro más de aquella generación de narradores con nervio, pero fue Rafael Azcona quien más perduró en primera línea.

Y todo lo llevó adelante entre anécdotas y sonrisas de tertuliano, sin darle importancia. Esa fue la mejor arma de un autor que siempre dirigió su mirada a ras de suelo, allí donde sabía que la retórica no era operativa y las paradojas de la realidad se muestran con claridad meridiana. Las observamos en los, a menudo, grotescos avatares de Miguel, Antonio y otros sujetos en una Ibiza sujeta al choque cultural del turismo. Aquella isla pudo ser un paraíso, pero las alpargatas molestaban, el sol quemaba y la picaresca no siempre bastaba para disponer de dinero. Un paraíso, en definitiva, terrenal y, además, cercano al Madrid de El pisito (1957 y 2005) o Los ilusos (1958 y 2008), a la España provinciana de Plácido (1961) y a la tragedia grotesca de El verdugo (1963).

Han pasado muchos años. Al menos, los suficientes como para que la memoria nos juegue una mala pasada en su búsqueda de lo más soportable. Rafael Azcona no cedió a esa tentación. Los europeos nos recuerda que era preciso ser un ingenuo para pensar en los paraísos perdidos cuando la realidad indicaba que, en aquellas circunstancias, sólo eran una referencia que animaba a sobrevivir. Con esa voluntad, la del superviviente crítico, Rafael Azcona huyó de Madrid 
durante varios veraneos, disfrutó en Ibiza y nos dejó un testimonio duro, desolador, pero con la fuerza de lo que invita a la superación sin caer en la moralina. Fue, como decía Rafael Conte, un escritor realista. Y sonriente, para nuestra fortuna de lectores y espectadores.

\section{BIBLIOGRAFÍA}

AZCONA, Rafael, El pisito. Novela de amor e inquilinato, Madrid, Taurus.

- (1958), Los ilusos, Madrid, Arión.

- (1960), Los europeos, París, Libraire des Éditions Espagnoles.

- (1999), Estrafalario/1, Madrid, Alfaguara.

- (2005), El pisito. Novela de amor e inquilinato, ed. Juan A. Ríos Carratalá, Madrid, Cátedra.

- (2006), Los europeos, Barcelona, Tusquets.

- (2008), Los ilusos, La Coruña, Ediciones del Viento.

CASTRO, Fernando-Guillermo de (2003), La isla perdida. Memoria de una época de Ibiza, Barcelona, Ed. Mediterrània-Eivissa.

HARGUINDEY, Ángel S. (1998), Memorias de sobremesa. Conversaciones de Ángel S. Harguindey con Rafael Azcona y Manuel Vicent, Madrid, El País-Aguilar.

MURO, Miguel Ángel (1997), «El mito sexual español: Los europeos de Rafael Azcona», en Luis Alberto CABEZÓN (ed.), Rafael Azcona, con perdón, Logroño, I.E.R., pp. 165-190.

RÍOS CARRATALÁ, Juan A. (2005), Int. a Rafael AZCONA (2005: 11-106).

- (2008), La sonrisa del inútil. Imágenes de un pasado cercano, Alicante, Publicaciones de la Universidad de Alicante.

SÁNCHEZ HARGUINDEY, Ángel. Véase HARGUINDEY.

Fecha de recepción: 5 de mayo de 2008

Fecha de aprobación: 1 de octubre de 2008 